\title{
EBNA-1 titer gradient in families with multiple sclerosis indicates a genetic contribution
}

Julia Y. Mescheriakova, MD, Gijsbert P. van Nierop, PhD, Annemiek A. van der Eijk, MD, PhD, Karim L. Kreft, MD, PhD,* and Rogier Q. Hintzen, MD, PhD*

Neurol Neuroimmunol Neuroinflamm 2020;7:e872. doi:10.1212/NXI.0000000000000872

\section{Abstract}

\section{Objective}

In multiplex MS families, we determined the humoral immune response to Epstein-Barr virus nuclear antigen 1 (EBNA-1)-specific immunoglobulin $\gamma$ (IgG) titers in patients with MS, their healthy siblings, and biologically unrelated healthy spouses and investigated the role of specific genetic loci on the antiviral IgG titers.

\section{Methods}

IgG levels against EBNA-1 and varicella zoster virus (VZV) as control were measured. HLA$D R B 1^{*} 1501$ and $H L A-A^{*} 02$ tagging single-nucleotide polymorphisms (SNPs) were genotyped. We assessed the associations between these SNPs and antiviral IgG titers.

\section{Results}

OR for abundant EBNA-1 IgG was the highest in patients with MS and intermediate in their siblings compared with spouses. We confirmed that $H L A-D R B 1^{*} 1501$ is associated with abundant EBNA-1 IgG. After stratification for HLA-DRB1*1501, the EBNA-1 IgG gradient was still significant in patients with MS and young siblings compared with spouses. HLA- $A^{*} 02$ was not explanatory for EBNA-1 IgG titer gradient. No associations for VZV IgG were found.

\section{Conclusions}

In families with MS, the EBNA-1 IgG gradient being the highest in patients with MS, intermediate in their siblings, and lowest in biologically unrelated spouses indicates a genetic contribution to EBNA-1 IgG levels that is only partially explained by $H L A-D R B 1^{*} 1501$ carriership.
Correspondence

Dr. Kreft

k.kreft@erasmusmc.nl 


\section{Glossary}

EBNA-1 = EBV nuclear antigen 1; EBV = Epstein-Barr virus; IgG = immunoglobulin; SNP = single-nucleotide polymorphism; VCA = virus capsid antigen; VZV = varicella zoster virus.

Familial clustering in multiple sclerosis (MS) is supportive for strong genetic determinants in MS etiology. The HLA$D R B 1^{*} 1501$-containing haplotype is the strongest genetic MS-associated genetic risk factor, whereas $H L A-A^{*} 02$ has a protective effect on MS. ${ }^{1,2}$ In addition, more than 200 nonHLA MS susceptibility loci with modest ORs have been identified. ${ }^{3}$ The associated genetic factors are seen more often in familial MS than in nonfamilial MS. ${ }^{4,5}$

Besides genetic factors, environmental factors contribute to the risk of developing $\mathrm{MS}^{6}{ }^{6}$ A recent meta-analysis of twin studies showed that environmental influences contribute for $21 \%$ of MS liability variance. ${ }^{7}$ The major environmental risk factor is an infection with the Herpesviridae family member Epstein-Barr virus (EBV). ${ }^{8,9}$ Furthermore, immunoglobulin $\gamma$ (IgG) response to EBV nuclear antigen 1 (EBNA-1) is heritable for $22 \%-43 \%$, suggesting that host genetic factors are important in the immune response to EBV. ${ }^{10-12}$ In relation to EBV antibody titers in patients with MS and their twins and siblings, only a few small-sized studies were conducted that showed somewhat variable results. ${ }^{13-17}$

The aim of our study was to determine the influence of genetic factors on humoral immune response toward EBNA-1 in multiplex families with MS, siblings, and controls. We hypothesized that because of shared genetic pool of patients with MS, their healthy siblings might have an increased IgG response to EBNA-1 compared with unrelated controls. Therefore, we determined serum EBNA-1 and varicella zoster virus (VZV) IgG as a control herpesvirus not associated with the development of $\mathrm{MS}^{18}$ in these 3 groups and assessed the influence of $H L A-D R B 1^{*} 1501$ and $H L A-A^{*} 02$ on antiviral titers.

\section{Methods}

\section{Study participants}

Most participants (257 patients with MS and 173 unaffected siblings from 136 multiplex families with MS and their 135 unrelated healthy spouses) were included from the still ongoing study on gene-environment interaction in MS in the Netherlands. In this study, multiplex families with MS are included, in which at least one first- or second-degree relative of an affected proband was also diagnosed with MS. The remaining participants (44 patients with MS, 25 unaffected siblings, and 39 healthy spouses) were included from the Genetic Research in Isolated Populations study. Details of ascertainment are described elsewhere. ${ }^{19}$ The diagnosis of MS in all patients was evaluated according to the standard diagnostic criteria. ${ }^{20,21}$

\section{Serologic testing}

Sera samples were collected and stored at $-80^{\circ} \mathrm{C}$. Serum EBNA$1 \mathrm{IgG}$ and VZV IgG levels were determined using well-validated chemiluminescent assays (Liaison XL, DiaSorin) according to the manufacturers' instruction. In samples negative for EBNA-1, antivirus capsid antigen (VCA) IgG (DiaSorin) was measured to ascertain EBV seroprevalence. If antibody levels were above the threshold of the assay, the samples were diluted 20-fold using sample diluent (DiaSorin) and reanalyzed. EBNA-1 and VCA double seronegative and VZV seronegative individuals were omitted from further analyses to prevent bias.

\section{Genotyping}

Genomic DNA was isolated using standardized methods. ${ }^{22}$ MS-associated single-nucleotide polymorphisms (SNPs; table e-1, links.lww.com/NXI/A297) were genotyped using the Sequenom platform according to manufacturers' instruction. The average genotype call rate for both SNPs was 99\%.

\section{Statistical analysis}

Data were analyzed using SPSS version 25.0 (SPSS Inc), and GraphPad Prism5 (GraphPad) was used to construct the graphs. Cases with missing data were omitted. EBNA-1 and VZV IgG titers were not normally distributed, also not after log transformation (both $p<0.001$, Kolmogorov-Smirnov test). Therefore, IgG levels were dichotomized as above or below the 75th percentile of the levels of the spouses. We used 2-tailed $t$-test or nonparametric Mann-Whitney $U$ test to compare continuous variables. Chi-square test or Fisher exact test were used to analyze nominal data. Generalized linear models (GLM) were used for the pairwise comparison of the study groups in relation to EBNA-1 and VZV titers, adjusted for gender, and household (i.e., to which family the samples belong to). Dichotomized IgG levels were also used to assess the ORs (OR) for the MS risk SNPs. ORs and associated CIs were calculated using logistic regression. The number of homozygous SNP carriers for a minor allele in both SNPs was <50; therefore, the homozygous group was pooled with heterozygous allele carriers (table e-2, links.lww.com/NXI/A297) to improve power. Two-sided $p$-values less than 0.05 were considered significant. Significance is indicated in the figures as ${ }^{*} p<0.05,{ }^{* *} p<0.01,{ }^{* * *} p<0.001$. Bonferroni correction was applied to correct for multiple testing.

\section{Standard protocol approvals, registrations, and patient consents}

Written informed consent was obtained from all participants with approval from the medical ethical committee of the Erasmus MC (Rotterdam, the Netherlands).

\section{Data availability}

All data are available from the corresponding author. 


\section{Results}

This study included a total of 301 patients with MS, their 198 unaffected siblings, and 174 unrelated healthy spouse controls (see figure 1 for the study flowchart). Table 1 shows the clinical and demographic characteristics of the study population.

\section{EBNA-1 IgG titers were inversely correlated with age}

EBV seroprevalence in patients with MS was higher than in their spouses and their siblings (table 1). No differences were found in VZV seroprevalence between all study groups. A one-way analysis of variance showed that the effect of age at sampling was significant $\left(\mathrm{F}(2,662)=11.3, p=1.5 \times 10^{-5}\right)$. Patients with MS were significantly younger than siblings and spouses (table 1). Age was inversely correlated with EBNA-1 IgG titers (Spearmans $\rho=-0.1, p=1.3 \times 10^{-2}$ ), and age at sampling was lower in the group with high EBNA-1 titers ( $>75$ th percentile) (mean age 48.3 years, 95\% CI 46.8-49.8) compared with the group with low EBNA-1 IgG titers ( $<75$ th percentile) (mean age at sampling 50.6 years, $95 \%$ CI 49.4-51.9, adjusted $p=2.0 \times 10^{-2}$ ). Therefore, we stratified all data into 2 age groups by using the median age, i.e., younger than 50 (young, $<50$ years) and older than 50 years of age at sampling (old, $>50$ years). Young patients with MS had higher EBNA-1 IgG titers compared with elderly patients with $\mathrm{MS}(\mathrm{OR}=1.7,95 \%$ CI $1.0-2.7$, adjusted $\left.p=3.5 \times 10^{-2}\right)$.

\section{EBNA-1 IgG titers were highest in patients with MS, intermediate in siblings, and lowest in their spouses}

Young patients with MS ( $<50$ years) had an increased risk for high EBNA-1 IgG titers ( $>75$ th percentile) compared with spouses (figure $2 \mathrm{~A}$ ). In addition, young siblings had an increased risk for high EBNA-1 IgG titers compared with spouses (figure 2A). In this age group, patients with MS were more likely to have high EBNA-1 IgG titers compared with siblings ( $\mathrm{OR}=2.7,95 \%$ CI 1.5-5.0, adjusted $p=2.0 \times 10^{-3}$ ). In addition, elderly patients with MS ( $>50$ years) had an increased risk for high EBNA-1 titers

Figure 1 Flowchart of the study

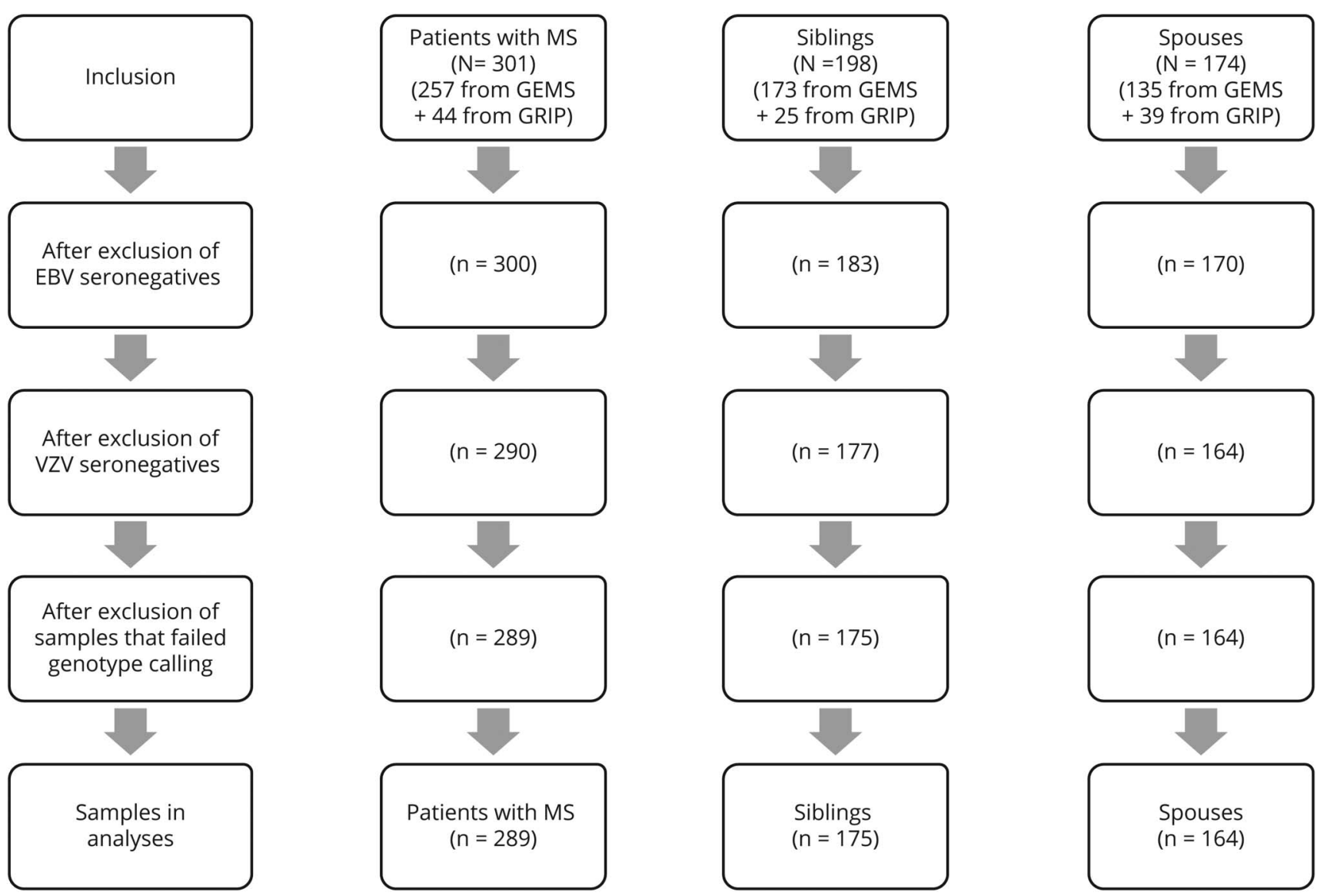

Only genotyped EBV (determined as EBV nuclear antigen 1 or viral capsid antigen IgG positive individuals) and VZV IgG-seropositive individuals were included in this study. EBV = Epstein-Barr virus; GEMS = study on gene-environment interaction in MS; GRIP = genetic research in isolated populations program; IgG = immunoglobulin; VZV = varicella zoster virus. 
Table 1 Clinical and demographic characteristics of patients with MS, siblings, and spouses

\begin{tabular}{|c|c|c|c|c|}
\hline & MS patients $N=301$ & Siblings $N=198$ & Spouses $N=174$ & $p$ Value \\
\hline $\begin{array}{l}\text { Gender }(\mathrm{N}) \\
\text { Female:male ratio }\end{array}$ & $\begin{array}{l}206: 95 \\
2.2: 1\end{array}$ & $\begin{array}{l}93: 105 \\
0.9: 1\end{array}$ & $\begin{array}{l}68: 106 \\
0.6: 1\end{array}$ & $1.8 \times 10^{-10}$ \\
\hline Age at sampling (y) & $46.9 \pm 12.6$ & $51.7 \pm 12.2$ & $51.1 \pm 12.1$ & $\begin{array}{l}\text { Between-groups: } \\
1.5 \times 10^{-5} \\
\text { MS vs Sibs: } 6.8 \times 10^{-5} \\
\text { MS vs spouses: } 0.1 \times 10^{-2}\end{array}$ \\
\hline Age at disease onset (y) & $33 \pm 10$ & - & - & - \\
\hline EDSS (median) & 3.5 & - & - & - \\
\hline MSSS & $4.7 \pm 2.7$ & - & - & - \\
\hline Disease duration (y) & $15 \pm 11$ & - & - & - \\
\hline RR-MS & $207(68.8 \%)$ & - & - & - \\
\hline CIS & $15(5.0 \%)$ & & & \\
\hline SP-MS & $41(13.6 \%)$ & & & \\
\hline PP-MS & $38(12.6 \%)$ & & & \\
\hline EBV seropositive & 300 (99.7\%; 95\% Cl 99.0-100.0) & 183 (92.4\%; 95\% Cl 88.7-96.1) & 170 (97.7\%; 95\% Cl 95.5-99.9) & $1.6 \times 10^{-5}$ \\
\hline VZV seropositive & 291 (96.7\%; 95\% Cl 94.7-98.7) & 190 (96.0\%; 95\% Cl 93.2-98.7) & 168 (96.6\%; 95\% Cl 93.8-99.3) & 0.9 \\
\hline
\end{tabular}

Abbreviations: $\mathrm{CIS}=$ clinically isolated syndrome; EBV = Epstein-Barr virus; EDSS = Expanded Disability Status Scale; MSSS = MS Severity Score; N = number; $\mathrm{PP}=$ primary progressive; $\mathrm{RR}$ = relapsing-remitting; $\mathrm{SP}=$ secondary progressive; $\mathrm{VZV}$ = varicella zoster virus.

Means and SDs are shown unless otherwise specified.

compared with spouses and their old siblings (figure $2 \mathrm{~A}$ ). There was no association between high VZV antibody titers and the study groups (figure 2B). EBNA-1 and VZV antibody titers were further not associated with gender, clinical disease course, or disease duration (data not shown).

Figure 2 Patients with MS and their siblings have increased risk of high EBNA-1 titers compared with spouses

A

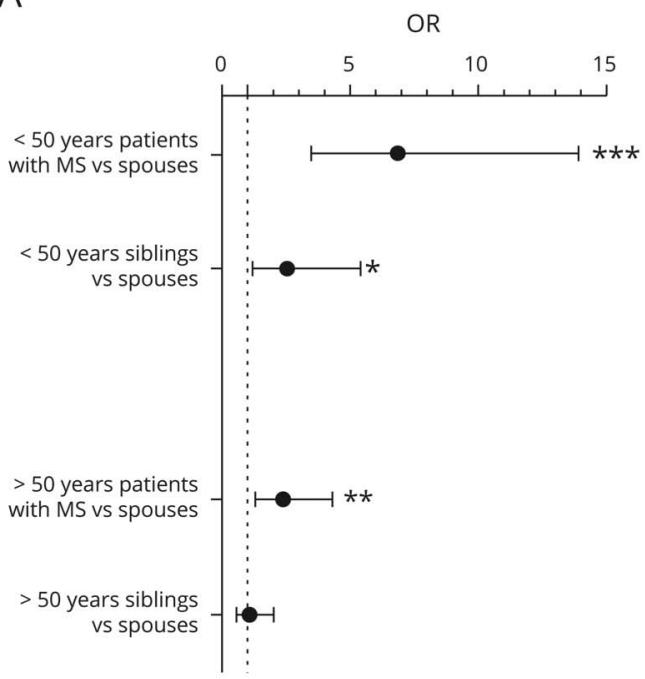

High EBNA-1 IgG titers
B

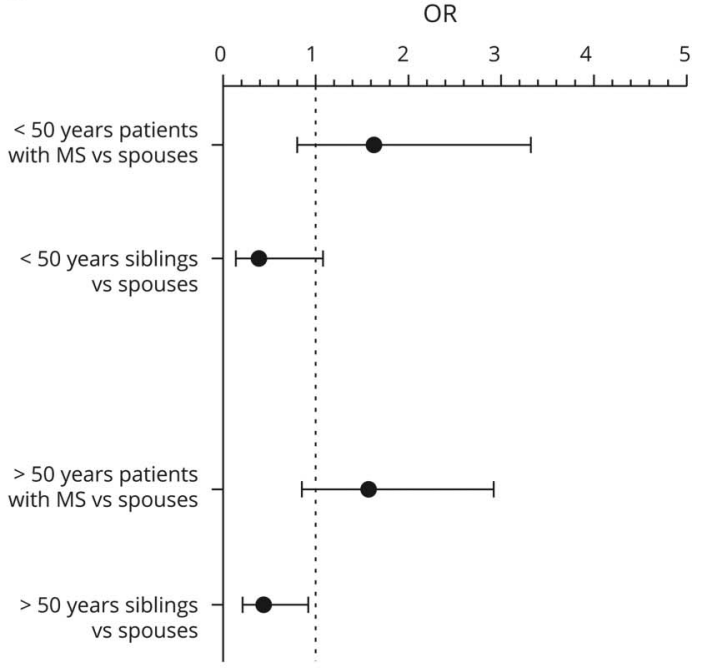

High VZV IgG titers

(A) OR for high EBNA-1 IgG titers (>75th percentile) is increased in patients with MS in both age categories and siblings younger than 50 years of age compared with spouses, suggesting that patients with MS and their siblings are more likely to have higher EBNA-1 IgG titers compared with spouses. (B) No differences in OR for high VZV IgG titers were found between patients with MS and siblings in comparison to the spouses. ORs were calculated by means of logistic regression analysis and GLM were used for between-group comparisons with Bonferroni-corrected and adjusted $p$-values for gender, disease status, and household. The whiskers indicate $95 \% \mathrm{Cl}$. Dashed line in each graph represents the reference group (spouses). EBNA-1 = EBV nuclear antigen 1; GLM = generalized linear model; IgG = immunoglobulin; VZV = varicella zoster virus. 


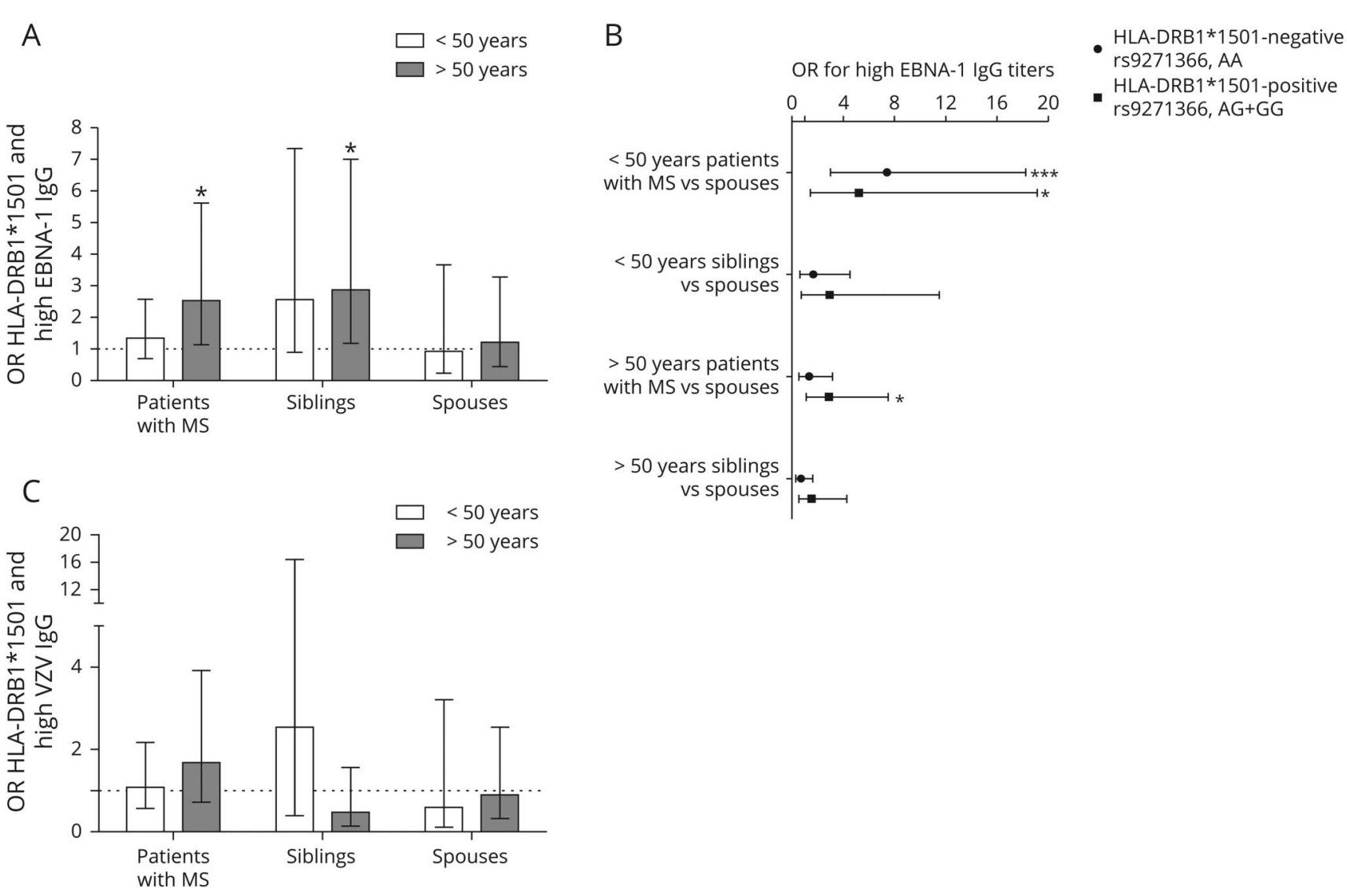

(A) ORs for the association between HLA-DRB1*1501 carriership and high EBNA-1 IgG titers were calculated for patients with MS, siblings, and spouses in 2 age categories. HLA-DRB1*1501 carriership is associated with high EBNA-1 IgG titers in old patients with MS and siblings. (B) OR for high EBNA-1 IgG titers (>75th percentile) is increased in young patients with MS vs spouses in both HLA-DRB1*1501-positive and negative individuals. In older patients with MS compared with controls, OR for high EBNA-1 IgG titers is only increased in HLA-DRB1*1501-positive individuals. (C) HLA-DRB1*1501 is not associated with high VZV IgG titers in all study groups. Logistic regression analyses were performed to calculate ORs, and GLM was used for between-group comparisons with Bonferroni corrected and adjusted $p$-values for gender, disease status and household. The whiskers indicate $95 \% \mathrm{Cl}$. EBNA-1 = EBV nuclear antigen 1 ; GLM = generalized linear model; IgG = immunoglobulin; VZV = varicella zoster virus.

\section{HLA-DRB1*1501 carriership is associated with high EBNA-1 IgG in older patients with MS and their siblings}

The risk allele ( $\mathrm{G}$ allele) frequency of the $H L A-D R B 1^{*} 1501$ tagging SNP (rs9271366) was higher in patients with MS (39\%; OR = 3.1 95\% CI 2.2-4.4) and siblings (28\%; OR = 1.9 95\% CI 1.3-2.8) when compared with spouses (17\%). HLA$D R B 1^{*} 1501$ was significantly associated with $\mathrm{MS}(\mathrm{OR}=4.2$, $95 \%$ CI 2.7-6.6, adjusted $p=7.4 \times 10^{-10}$ ). In both patients with MS and study subjects without MS, HLA-DRB1*1501 was associated with elevated EBNA-1 IgG levels (OR $=1.695 \% \mathrm{CI}$ $1.0-2.6$, adjusted $p=4.4 \times 10^{-2}$ and $\mathrm{OR}=2.2,95 \% \mathrm{CI} 1.4-3.6$ adjusted $p=2.0 \times 10^{-3}$, respectively). By contrast, VZV IgG titers were not associated with $H L A-D R B 1^{*} 1501$.

HLA-DRB1*1501 risk genotype was associated with high EBNA-1 IgG titers in older patients with MS and older siblings (figure 3A).

OR for high EBNA-1 IgG titers was increased in young patients with MS vs spouses irrespective of HLA-DRB1 ${ }^{*} 1501$ carriership (figure 3B). In older patients with MS compared with controls, OR for high EBNA-1 IgG titers is only increased in HLA-DRB1*1501-positive individuals (figure 3, A and B).

In the HLA-DRB1*1501-negative group (AA genotype), young patients with MS had higher EBNA-1 IgG titers than elderly patients with $\mathrm{MS}(\mathrm{OR}=2.7,95 \%$ CI 1.1-6.1, adjusted $p=1.4 \times$ $10^{-2}$ ). In addition, young patients with MS had higher EBNA-1 IgG titers than siblings ( $\mathrm{OR}=4.4,95 \% \mathrm{CI} 1.7-11.2$, adjusted $\left.p=2.0 \times 10^{-3}\right)$ and spouses $(\mathrm{OR}=7.4,95 \%$ CI 3.0-18.3, adjusted $p=1.4 \times 10^{-5}$ ).

There was no association between HLA-DRB1 ${ }^{*} 1501$ and high VZV IgG titers (>75th percentile) in all study groups in both age categories (figure 3C).

\section{$H L A-A * 02$ is not associated with MS and EBNA-1 IgG titers}

The HLA- $A^{*} 02$ tagging SNP (rs6457110) was not associated with MS in our study (OR $=0.995 \%$ CI 0.6-1.2, $p=0.4$ adjusted for age, gender, household, and HLA-DRB1 ${ }^{*} 1501$ ). 
Figure 4 The risk of high EBNA-1 IgG is associated with age, HLA-DRB1*1501 carriership, having MS, or being a family member of a patient with MS

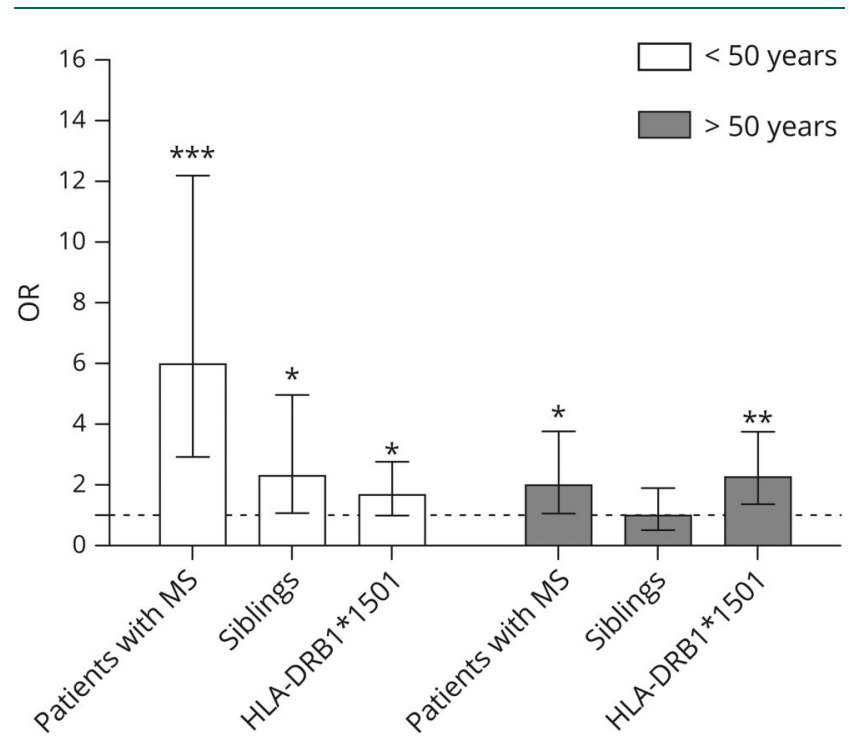

The risk of high EBNA-1 IgG is associated with age, having MS, or being a family member of a patient with MS, and HLA-DRB1*1501 carriership. EBNA1 = EBV nuclear antigen 1; IgG = immunoglobulin.

The $H L A-A^{*} 02$ tagging SNP was also not associated with EBNA-1 IgG and VZV titers when stratified for all study groups and age categories (data not shown).

\section{Risk for high EBNA-1 IgG titers is increased in patients with MS, HLA-DRB1*1501 carriers, and young siblings of patients with MS}

Finally, we performed a multivariate analysis to assess the individual effect of having MS or being a family member of a patient with MS, and having HLA-DRB1*1501, stratified for age. In both age categories, having $\mathrm{MS}$ is an independent risk factor for high EBNA-1 IgG levels, and this effect is independent of HLA$D R B 1^{*} 1501$. In addition, being a young family member of a patient with MS increases the risk of abundant EBNA-1 IgG (figure 4). These results underscore the importance of the host genetics on the humoral immune response against EBV. Moreover, it indicates the importance of other genetic factors, for example, other polymorphisms and epigenetic changes over time, contributing to the humoral immune response against EBV in MS.

\section{Discussion}

We showed a gradient in EBNA-1 IgG being the highest in patients with MS, intermediate in their siblings, and the lowest in spouses. Congruent with our results, Comabella et al. ${ }^{14}$ found an increased IgG response to EBNA-1 in patients with MS compared with healthy siblings without a biologically unrelated control group. A very small study using a nonlinear EBNA-1 IgG quantification method assessing patients with MS and their siblings in comparison to unrelated controls showed the results comparable with our study. ${ }^{17}$
The observed EBNA-1 IgG titer gradient in our study suggests a genetic contribution of MS-related SNPs to EBNA-1 IgG titers. Indeed, in previous studies, first-degree family members of patients with MS showed to have higher genetic load for MS-associated risk SNPs compared with spouses. ${ }^{4,5}$ We confirmed that $H L A-D R B 1^{*} 1501$ carriership significantly associates with high EBNA-1 IgG titers. A recent study showed that HLA-DRB1*1501 carriership also in healthy controls, fully unrelated to patients with MS, is associated with enhanced EBNA-1 IgG levels. ${ }^{23}$ The high prevalence of $H L A-D R B 1^{*} 1501$ in patients with MS, intermediate in siblings, and low in spouses could partly explains the gradient observed in EBNA-1 IgG titers in the 3 groups. After stratification for $H L A-D R B 1^{*} 1501$, the observed gradient was still present in young patients with $M S$, siblings and spouses. This implies that HLA-DRB1 $1^{*} 1501$ is not the only player for the generation of the anti-EBV immune response in young patients with MS. The $H L A-A^{*} 02$ tagging SNP was not associated with the EBNA-1 IgG titers. Likely, other genetic factors besides HLA-DRB1*1501 contribute to increased EBNA-1 IgG response. ${ }^{24,25}$ Next to shared genetics, shared environment between patients with MS and their siblings in early life, when EBV infection typically occurs, might partly be responsible for the found EBNA-1 IgG gradient.

Moreover, we found that high EBNA-1 titers were associated with low age. When stratified into study groups, EBNA-1 IgG was higher in young patients with MS compared with elderly patients with MS. This could be due to a particular phenomenon called immunosenescence, i.e., a gradual negative dysregulation of the immune system in the elderly. ${ }^{26}$ There is overwhelming evidence that the amount of antibodies induced after an immunization response is strongly reduced with physiologic aging and that titers decline occur more rapidly in elderly. ${ }^{27,28}$ In our study, we found that particularly in elderly patients and their elderly siblings, high EBNA-1 IgG titers were associated with the presence of the $H L A-D R B 1^{*} 1501$. This may suggest that a certain genetic make-up is needed to react adequately to the EBV infection in elderly. Indeed, $H L A-D R B 1^{*} 1501$ is strongly correlated with EBNA-1 IgG. ${ }^{29}$ There was a limitation to our study. Because of a moderate sample size, we limited ourselves to testing only $H L A-D R B 1^{*} 1501$ and $H L A-A^{*} 02$ loci in the genetic association analyses in relation to viral titers. Because of a suggestive genetic contribution on the EBNA-1 IgG response, it would be interesting to assess how non-HLA MS risk SNPs are involved in this process.

In summary, our study showed that EBNA-1 IgG titers were highest in patients with MS, intermediate in siblings, and low in spouses, which suggests a strong genetic contribution on the EBNA-1 response that is partially associated with HLA$D R B 1^{*} 1501$. Correcting for HLA-DRB1 ${ }^{*} 1501$ did not abrogate this association, which suggests that additional genetic factors may contribute to this gradient. Further large genetic studies assessing MS genetics and EBNA-1 IgG responses are 
needed to determine which MS risk SNP are contributing to the enhanced EBNA-1 IgG response in MS. In addition, EBNA-1 IgG titers were higher in young patients with MS compared with elderly patients with MS. To study the complex interaction between environmental and genetic factors, age needs to be considered. Potentially, this relates to the predominant relapsing-remitting disease progression in young compared with the more progressive disease in older patients with MS.

\section{Acknowledgment}

The authors would like to thank all patients with MS and their families for their participation in this study. A special thank you to Janienne Klaasse and Sandra M.J. Scherbeijn for sample handling and technical assistance with the quantification of the antiviral titers.

Deceased: Rogier Q. Hintzen, MD, PhD.

\section{Study funding}

MS centre ErasMS is financially supported by the Dutch MS Research Foundation.

\section{Disclosure}

J.Y. Mescheriakova, G.P. van Nierop, A.A. van der Eijk, and K.L. Kreft report no disclosures relevant to the manuscript. R.Q. Hintzen is deceased; disclosures are not included for this author. Go to Neurology.org/NN for full disclosures.

\section{Publication history}

Received by Neurology: Neuroimmunology \& Neuroinflammation March 3, 2020. Accepted in final form July 7, 2020.

\section{Appendix Authors}

\begin{tabular}{lll}
\hline Authors & Location & Contribution \\
\hline $\begin{array}{ll}\text { Julia Y. } \\
\text { Mescheriakova, }\end{array}$ & $\begin{array}{l}\text { Erasmus MC, University } \\
\text { Medical Center, }\end{array}$ & $\begin{array}{l}\text { Designed and } \\
\text { conceptualized }\end{array}$ \\
& Rotterdam, The & the study, major \\
Netherlands & role in acquisition \\
& & of data, analyzed \\
& the data, and drafted \\
& the manuscript
\end{tabular}

\begin{tabular}{lll}
\hline Gijsbert P. van & Erasmus MC, University & Data acquisition, \\
Nierop, PhD & Medical Center, & interpreted the data, \\
& Rotterdam, The & and revised the \\
Netherlands & manuscript for \\
& & intellectual \\
& content
\end{tabular}

\begin{tabular}{lll}
\hline $\begin{array}{l}\text { Annemiek A. } \\
\text { van der Eijk, MD, } \\
\text { PhD }\end{array}$ & $\begin{array}{l}\text { Erasmus MC, University } \\
\text { Medical Center, } \\
\text { Rotterdam, The } \\
\text { Netherlands }\end{array}$ & $\begin{array}{l}\text { Data acquisition } \\
\text { and revised the } \\
\text { manuscript for } \\
\text { intellectual } \\
\text { content }\end{array}$ \\
\hline $\begin{array}{l}\text { Karim L. Kreft, } \\
\text { MD, PhD }\end{array}$ & $\begin{array}{ll}\text { Erasmus MC, University } \\
\text { Medical Center, } \\
\text { Rotterdam, The } \\
\text { Netherlands }\end{array}$ & $\begin{array}{l}\text { Conceptualized } \\
\text { the study, analyzed } \\
\text { and interpreted the } \\
\text { data, and revised } \\
\text { the manuscript for } \\
\text { intellectual } \\
\text { content }\end{array}$ \\
& &
\end{tabular}

Appendix (continued)

\begin{tabular}{|c|c|c|}
\hline Authors & Location & Contribution \\
\hline $\begin{array}{l}\text { Rogier Q. } \\
\text { Hintzen, MD, } \\
\text { PhD }\end{array}$ & $\begin{array}{l}\text { Erasmus MC, University } \\
\text { Medical Center, } \\
\text { Rotterdam, The } \\
\text { Netherlands }\end{array}$ & $\begin{array}{l}\text { Designed and } \\
\text { conceptualized the study, } \\
\text { major role in the acquisition } \\
\text { of data, interpreted the } \\
\text { data, and partly revised the } \\
\text { manuscript for intellectual } \\
\text { content }\end{array}$ \\
\hline
\end{tabular}

\section{References}

1. Patsopoulos NA, Barcellos LF, Hintzen RQ, et al. Fine-mapping the genetic association of the major histocompatibility complex in multiple sclerosis: HLA and nonHLA effects. PLoS Genet 2013;9:e1003926.

2. Fogdell-Hahn A, Ligers A, Grønning M, Hillert J, Olerup O. Multiple sclerosis: a modifying influence of HLA class I genes in an HLA class II associated autoimmune disease. Tissue Antigens 2000;55:140-148.

3. Patsopoulos NA, Baranzini SE, Santaniello A, et al. Multiple sclerosis genomic map implicates peripheral immune cells and microglia in susceptibility. Science 2019;80:eaav7188.

4. Gourraud PA, McElroy JP, Caillier SJ, et al. Aggregation of multiple sclerosis genetic risk variants in multiple and single case families. Ann Neurol 2011;69:65-74.

5. Mescheriakova JY, Broer L, Wahedi S, et al. Burden of genetic risk variants in multiple sclerosis families in the Netherlands. Mult Scler J Exp Transl Clin 2016;2:2055217316648721.

6. Belbasis L, Bellou V, Evangelou E, Ioannidis JPA, Tzoulaki I. Environmental risk factors and multiple sclerosis: an umbrella review of systematic reviews and metaanalyses. Lancet Neurol 2015;14:263-273.

7. Fagnani C, Neale MC, Nisticò L, et al. Twin studies in multiple sclerosis: a metaestimation of heritability and environmentality. Mult Scler 2015;21:1404-1413.

8. Thacker EL, Mirzaei F, Ascherio A. Infectious mononucleosis and risk for multiple sclerosis: a meta-analysis. Ann Neurol 2006;59:499-503.

9. Ascherio A, Munger KL, Lennette ET, et al. Epstein-Barr virus antibodies and risk of multiple sclerosis: a prospective study. J Am Med Assoc 2001;286:3083-3088.

10. Rubicz R, Yolken R, Drigalenko E, et al. A genome-wide integrative genomic study localizes genetic factors influencing antibodies against Epstein-Barr virus nuclear antigen 1 (EBNA-1). PLoS Genet 2013;9:e1003147.

11. Rubicz R, Leach CT, Kraig E, et al. Genetic factors influence serological measures of common infections. Hum Hered 2011;72:133-141.

12. Sallah $\mathrm{N}$, Carstensen $\mathrm{T}$, Wakeham $\mathrm{K}$, et al. Whole-genome association study of antibody response to Epstein-Barr virus in an African population: a pilot. Glob Heal Epidemiol Genomics 2017;2:e18.

13. Bergkvist M, Sandberg-Wollheim M. Serological differences in monozygotic twin pairs discordant for multiple sclerosis. Acta Neurol Scand 2001;104:262-265.

14. Comabella M, Montalban X, Horga A, et al. Antiviral immune response in patients with multiple sclerosis and healthy siblings. Mult Scler 2010;16:355-358.

15. Kinnunen E, Valle M, Piirainen L, et al. Viral antibodies in multiple sclerosis: a nationwide co-twin study. Arch Neurol 1990;47:743-746.

16. Ristori G, Mechelli R, Anderson J, et al. Antiviral immune response in patients with multiple sclerosis, healthy siblings and twins. Mult Scler 2010;16:1527-1528.

17. Sumaya CV, Myers LW, Ellison GW, Ench Y. Increased prevalence and titer of Epstein-Barr virus antibodies in patients with multiple sclerosis. Ann Neurol 1985;17:371-377.

18. Burgoon MP, Cohrs RJ, Bennett JL, et al. Varicella zoster virus is not a disease-relevant antigen in multiple sclerosis. Ann Neurol 2009;65:474-479.

19. Hoppenbrouwers IA, Cortes LM, Aulchenko YS, et al. Familial clustering of multiple sclerosis in a Dutch genetic isolate. Mult Scler 2007:17-24.

20. McDonald WI, Compston A, Edan G, et al. Recommended diagnostic criteria for multiple sclerosis: guidelines from the International Panel on the Diagnosis of Multiple Sclerosis. Ann Neurol 2001;50:121-127.

21. Poser CM, Paty DW, Scheinberg L, et al. New diagnostic criteria for multiple sclerosis: guidelines for research protocols. Ann Neurol 1983;13:227-231.

22. Miller SA, Dykes DD, Polesky HF. A simple salting out procedure for extracting DNA from human nucleated cells. Nucleic Acids Res 1988;16:1215.

23. Hedström AK, Huang J, Michel A, et al. High levels of Epstein-Barr virus nuclear antigen-1-specific antibodies and infectious mononucleosis act both independently and synergistically to increase multiple sclerosis risk. Front Neurol 2020;10:1368.

24. Kreft KL, Van Nierop GP, Scherbeijn SMJ, et al. Elevated EBNA-1 IgG in MS is associated with genetic MS risk variants. Neurol Neuroimmunol Neuroinflammation 2017;4:e406. 10.1212/NXI.0000000000000406.

25. Zhou Y, Zhu G, Charlesworth JC, et al. Genetic loci for Epstein-Barr virus nuclear antigen-1 are associated with risk of multiple sclerosis. Mult Scler 2016;22:1655-1664.

26. DeWitt JC, Luebke RW. Immunological aging. In: Comprehensive Toxicology, 2nd ed. Oxford: Elsevier; 2018.

27. Weinberger B, Herndler-Brandstetter D, Schwanninger A, Weiskopf D, GrubeckLoebenstein B. Biology of immune responses to vaccines in elderly persons. Clin Infect Dis 2008;46:1078-1084.

28. Frasca D, Blomberg BB. Effects of aging on B cell function. Curr Opin Immunol 2009; 21:425-430.

29. Simon KC, van der Mei IA, Munger KL, et al. Combined effects of smoking, anti-EBNA antibodies, and HLA-DRB1*1501 on multiple sclerosis risk. Neurology 2010;74:1365-1371. 


\section{Neurology \\ Neuroimmunology \& Neuroinflammation}

\section{EBNA-1 titer gradient in families with multiple sclerosis indicates a genetic contribution}

Julia Y. Mescheriakova, Gijsbert P. van Nierop, Annemiek A. van der Eijk, et al.

Neurol Neuroimmunol Neuroinflamm 2020;7;

DOI 10.1212/NXI.0000000000000872

This information is current as of August 13, 2020

\section{Updated Information \& \\ Services}

References

Citations

Permissions \& Licensing

Reprints including high resolution figures, can be found at:

http://nn.neurology.org/content/7/6/e872.full.html

This article cites 27 articles, 0 of which you can access for free at: http://nn.neurology.org/content/7/6/e872.full.html\#\#ref-list-1

This article has been cited by 1 HighWire-hosted articles: http://nn.neurology.org/content/7/6/e872.full.html\#\#otherarticles

Information about reproducing this article in parts (figures,tables) or in its entirety can be found online at:

http://nn.neurology.org/misc/about.xhtml\#permissions

Information about ordering reprints can be found online: http://nn.neurology.org/misc/addir.xhtml\#reprintsus

Neurol Neuroimmunol Neuroinflamm is an official journal of the American Academy of Neurology.

Published since April 2014, it is an open-access, online-only, continuous publication journal. Copyright

Copyright $\odot 2020$ The Author(s). Published by Wolters Kluwer Health, Inc. on behalf of the American Academy of Neurology.. All rights reserved. Online ISSN: 2332-7812.

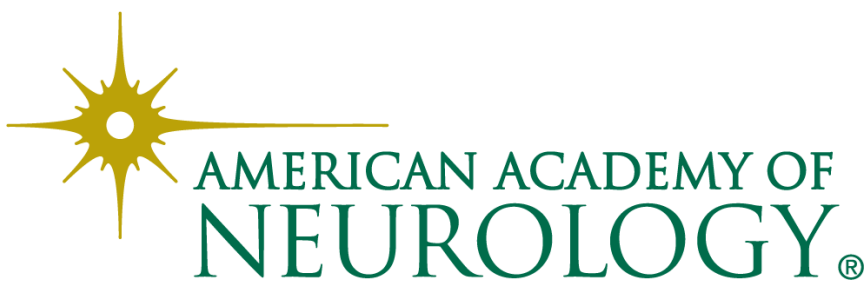

